\title{
Orientation-dependent solid solution strengthening in zirconium: a nanoindentation study
}

\author{
Arijit Lodh ${ }^{1, *}$ (D), Prita Pant $^{2}$ (1), Gulshan Kumar $^{3}$ (D), K. V. Mani Krishna ${ }^{4}$ (D), Raghvendra Tewari ${ }^{4}$ (D), and \\ Indradev Samajdar ${ }^{2}$ (D) \\ ${ }^{1}$ School of Aerospace, Transport and Manufacturing, Cranfield University, Bedfordshire MK43 OAL, UK \\ ${ }^{2}$ Department of Metallurgical Engineering and Materials Science, Indian Institute of Technology Bombay, Mumbai 400076, India \\ ${ }^{3}$ Department of Mechanical Engineering, BITS Pilani, Dubai Campus, Dubai International Academic City (DIAC), 345055 Dubai, UAE \\ ${ }^{4}$ Materials Science Division, Bhabha Atomic Research Centre, Mumbai 400085, India
}

Received: 18 July 2019

Accepted: 6 December 2019

Published online:

17 December 2019

(C) The Author(s) 2019

\begin{abstract}
Orientation-dependent solid solution strengthening was explored through a combined microtexture plus nanoindentation study. Pure zirconium (6N purity crystal-bar $\mathrm{Zr}$ ) and commercial Zircaloy-2 were investigated for comparison. Local mechanical properties were estimated through finite element (FE) simulations of the unloading part of the nanoindentation load-displacement response. Combinations of 'averaging' scheme and constitutive relationship were used to resolve uncertainty of FE-extracted mechanical properties. Comparing the two grades, non-basal oriented grains showed an overall hardening and increase in elastic modulus. In contrast, insignificant change was observed for basal (or near-basal) oriented grains. The strengthening of non-basal orientations appeared via elimination of the lowest hardness/stiffness values without a shift in the peak value. Such asymmetric development brought out the clear picture of orientation-dependent solid solution strengthening in zirconium.
\end{abstract}

\section{Introduction}

Zirconium alloys are used as in-reactor structural material in the thermal nuclear reactors [1-4]. Their selection is based on low-neutron-absorption cross section, excellent mechanical and corrosion properties at reactor working temperatures $[3,5,6]$. Any alloy development naturally needs to consider all these aspects. One of these is the aspect of enhancing the mechanical performance, more specifically, possibilities on enhanced strengthening. It is important to note that zirconium has a hexagonal crystal structure [7, 8]. This makes zirconium alloys anisotropic [8-11]. The orientation sensitivity of the mechanical properties is naturally of both academic and applied interest.

Anisotropy of single crystal zirconium has been discussed in the literature [12-17]. These studies were performed through conventional mechanical tests on large single crystals, hence they had experimental limitations. Nanoindentation, on the other hand, can serve as an alternative testing procedure, since

Address correspondence to E-mail: arijitlodh@gmail.com 
precise indentations can be made within a grain. This not only eliminates the complications of generating single crystals, but allows measurements on specific microstructural features. Nanoindentation experiments typically provide load-displacement data. Experiments and practices in mechanics, however, demand the stress-strain behavior. It is possible to convert [18-23] nanoindentation data to stress-strain plots, especially through numerical simulations. This conversion involves regression analysis, and hence the solutions may not be 'unique' [19, 20, 24-27]. In other words, a single nanoindentation load-displacement plot may be described by multiple stressstrain behaviors.

If the above-mentioned problem of 'non-uniqueness' is addressed, then nanoindentation can offer interesting insights into metal physics. Of interest to the present manuscript is the effect of alloying to the strengthening behavior at grain scale of a polycrystalline material. A precise indentation made at the center of grain and away from precipitates brings out the effect of solutes present when compared to a solute-free (or negligible solute) grain and ignores the grain size effect. For example, in high-purity thin films of aluminum single crystals the reported difference in hardness, between $\langle 111\rangle$ and $\langle 001\rangle$ grains, is $60 \%$. This difference scales with estimated differences in Taylor factor [28]. Grains or orientations of aluminum alloys with a similar difference in Taylor factor, however, show a hardness difference of about $10 \%$ [28]. Single crystals of $\mathrm{Mg}-\mathrm{Li}$ alloy show an increase in the strength of basal planes with $\mathrm{Li}$ addition [29]. However, prismatic and pyramidal planes are softened with $\mathrm{Li}$ addition [30]. This behavior is valid for a wide range of temperature. Similar behavior is observed with $\mathrm{Zn}$ addition in $\mathrm{Mg}$ single crystals [31]. In polycrystals, the strengthening effect increases with increase in alloying elements up to solubility limit. This increment is an overall response; however, the relative effect of alloying elements on solid solution strengthening for different orientations in a polycrystalline material remains undocumented.

A previous study [32] provides preliminary results on orientation sensitivity of nanohardness in crystalbar zirconium (6N purity) and Zircaloy-2. Though a finite element-based model predicted stress-strain behavior, the problem on non-unique solutions remained. This present contribution expands on the previous work [32] and provides a possibility to obtain a unique/precise stress-strain behavior from nanoindentations. Covering a wide range of similar orientations for two different grades of zirconium, this study expands the possibility to have an upper limit of orientation-dependent solid solution strengthening.

\section{Experimental details}

\section{Materials}

Two zirconium $(\mathrm{Zr})$ grades were investigated in this study. These were crystal-bar $\mathrm{Zr}$ (6N purity 99.9999 $\mathrm{wt} \% \mathrm{Zr}$ ) and commercial Zircaloy-2. The former was free from precipitates and had large grain size (in $\mathrm{mm})$. Zircaloy-2 is a commercial solid solution of zirconium with sub-micron intermetallic precipitates. (Chemical composition is listed in Table 1.) For processing of crystal-bar $\mathrm{Zr}$, the reader can refer to [3]. Samples of Zircaloy-2 were made from cast and forged Zircaloy-2 blocks, subjected to $40 \%$ cold rolling and subsequent recrystallization (1098 K for $24 \mathrm{~h})$. The resulting grain size $(\sim 15 \mu \mathrm{m})$ is sufficient to confine nanoindented plastic/deformation zones within the individual crystallites ( $\sim 2$ to $4 \mu \mathrm{m}$ indent size).

\section{Nanoindentation and electron backscattered diffraction (EBSD)}

Before nanoindentation and EBSD, all samples were electropolished using an electrolyte of 80:20 methyl alcohol and perchloric acid under $21 \mathrm{~V}$ at $233 \mathrm{~K}$. Nanoindentation tests were performed using a Hysitron Triboindenter $^{\mathrm{TM}}$ (TI 900). All nanoindents were made using a Berkovich tip in load-controlled mode to a maximum load of $5000 \mu \mathrm{N}$. Berkovich indenter is a three-sided pyramidal tip with half included angle of $70.3^{\circ}$. The contact area between indenter and material is different between spherical and Berkovich tip. Following the Oliver-Pharr

Table 1 Chemical composition of Zircaloy-2 (in wt $\%$ of alloying elements)

\begin{tabular}{llllll}
\hline $\mathrm{Sn}$ & $\mathrm{Fe}$ & $\mathrm{Cr}$ & $\mathrm{Ni}$ & $\mathrm{O}$ & $\mathrm{Zr}$ \\
\hline 1.54 & 0.15 & 0.12 & $<0.05$ & 0.12 & Balance \\
\hline
\end{tabular}


analysis method [33] and Hertzian contact model [34] for nanoindentation, one needs to find appropriate contact radius. If that is considered, then stress-strain behavior for spherical or circular tips is expected to be similar. Further, using the same loading module (the so-called high-load or low-load module in a nanoindenter) strains imposed and plastic zones established are noticeably higher for Berkovich. The sharp Berkovich indenter not only provides an expanded stress-strain response, but more effectively avoids influence (if any) of grain below the indenting grains. A triangular waveform was assumed with $1000 \mu \mathrm{N} / \mathrm{s}$ loading and unloading rate and $10 \mathrm{~s}$ hold time. The maximum load was decided after a set of initial trial experiments by varying loads till projected area of indentation gets constant [35]. To avoid having any grain size effect, indents were placed carefully close to grain center in Zircaloy-2. From the respective load-displacement plots, hardness and reduced elastic modulus were estimated using the Oliver and Pharr analysis [33]. The indented samples were then scanned using EBSD (electron backscattered diffraction: TSL-OIM ${ }^{\mathrm{TM}}$ ) in a FEI ${ }^{\mathrm{TM}}$ Quanta-3D FEG (field emission gun) SEM (scanning electron microscope). Step size of $0.1 \mu \mathrm{m}$ and identical beam/ video conditions were maintained between the scans for comparison. Various precipitates may form during phase transformations in single-phase $\mathrm{Zr}$ alloys $[3,36]$. These hard intermetallic precipitates are referred to as '2nd phase' in the present work. They can be classified as: (1) $\mathrm{Zr}_{2}(\mathrm{FeNi})$-type intermetallic, (2) hexagonal $\mathrm{Zr}(\mathrm{CrFe})_{2}$ Laves phase precipitate and (3) $\mathrm{Zr}_{3} \mathrm{P}$ precipitates. Combining the inverse pole figure (IPF) and image quality (IQ) maps, nearboundary indents and indents close to the second phase were identified and subsequently omitted from the analysis.

\section{Finite element modeling}

A finite element (FE) model was formulated to simulate load-displacement behavior and to extract the values of yield stress and strain-hardening exponent. This was performed using a commercial finite element package, ABAQUS ${ }^{\mathrm{TM}}$, assuming axi-symmetric elasto-plastic specimen. As the Berkovich indenter is not axi-symmetric, the indenter was modeled as an elastically deformable equivalent conical indenterwith the same depth-to-area relationship and half included angle of $70.3^{\circ}$. An indenter tip radius of
$200 \mathrm{~nm}$ was assumed, and Fig. 1a justifies the reason of choosing the mentioned value. As per the application note of instrument makers (Hysitron ${ }^{\circledR}$ ) [37], the radius of curvature of a tip is typically three times larger than the contact depth drop off for hardness measurements on standard sample (e.g., fused quartz). For the present study, the same method was followed and it was found that hardness becomes constant after the contact depth value of $66 \mathrm{~nm}$.

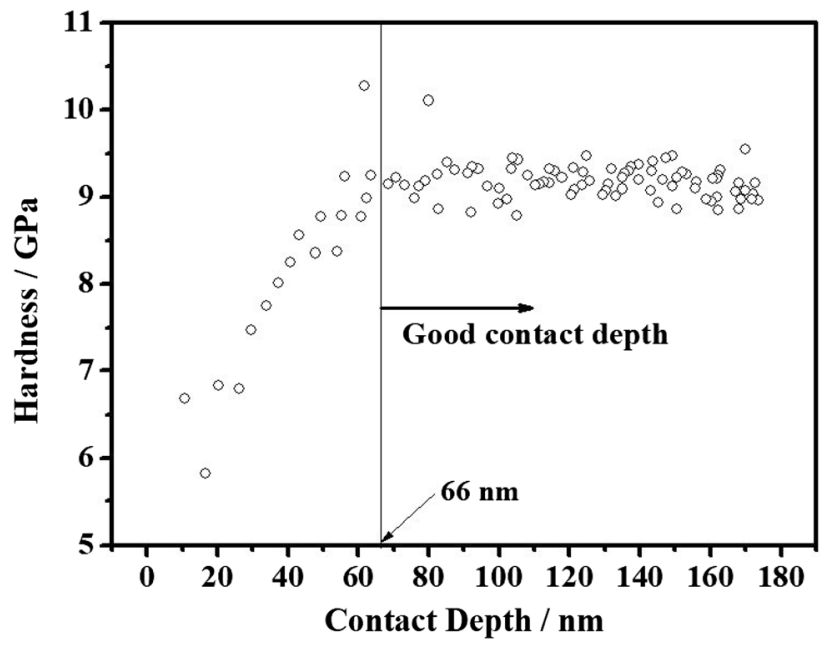

(a)

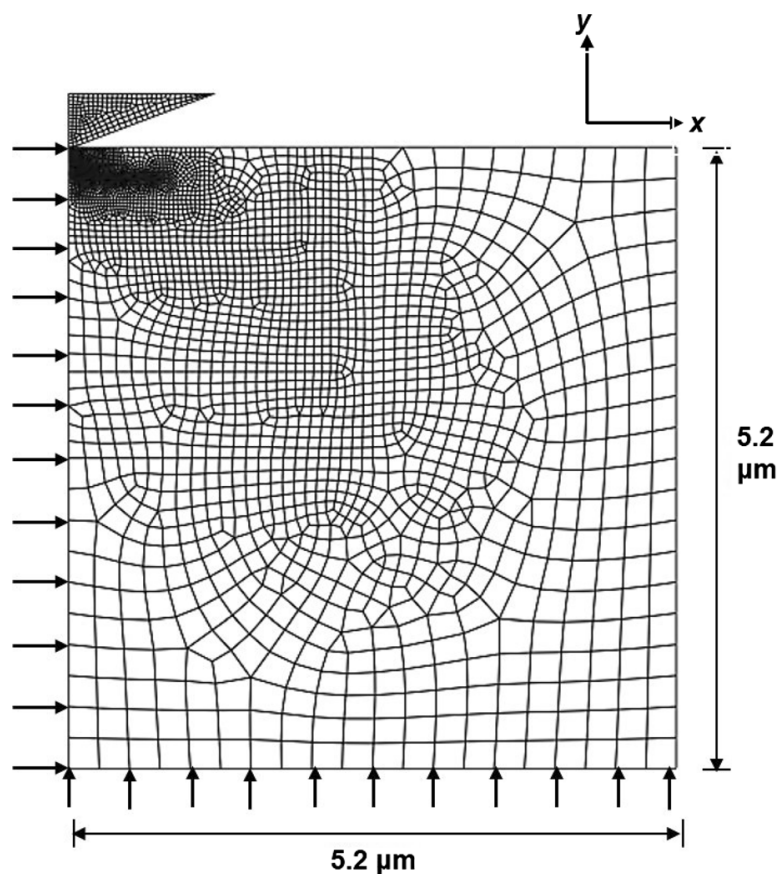

(b)

Figure 1 a Contact depth versus nanohardness of a standard sample to obtain indenter radius, $\mathbf{b}$ geometry and boundary conditions of the meshed FE (finite element) model. 
Based on this observation, tip radius was chosen as $200 \mathrm{~nm}$ (approximately $3 \times 66 \mathrm{~nm}$ ). Figure $1 \mathrm{~b}$ shows the meshed geometry of finite element model. Since the contact region is expected to experience very high stresses and undergo severe deformation, a very fine mesh was used in the sample using biased meshing technique. The specimen was assumed to be homogeneous and isotropic though the elastic modulus values varied as a function of grain orientation (obtained from nanoindentation measurements). Both indenter and specimen were modeled with four-node and three-node linear axi-symmetric elements, respectively. The coefficient of friction between indenter and specimen was kept as 0.20. During the simulation, the bottom part of the sample was fixed. Left side of the sample and indenter were allowed to move in $y$-direction only with fixed $x$-direction movement. Pressure was applied on indenter, corresponding to experimental load profile. The unloading part was simulated as taking the indenter to the original position. After the simulation, load was calculated from the sum of the reaction forces from the bottom nodes of the specimen, and sample displacement was measured from the nodal displacements close to the contact region.

For the simulations, elastic properties of diamond were used for the indenter: elastic modulus $1140 \mathrm{GPa}$ and $v=0.07[33,35]$. For the specimen, $v$ was kept constant at 0.34 [38]. In the present finite element model, no size effect is present. Specimen geometry denotes single crystal or orientation. In experiments, indents were placed close to the grain center with large enough grain size. Equation (1) described this as,

$\sigma= \begin{cases}E \varepsilon_{\mathrm{e}} & \text { when } \sigma<\sigma_{\mathrm{y}} \\ K \varepsilon_{\mathrm{p}}^{n} & \text { when } \sigma>\sigma_{\mathrm{y}}\end{cases}$

where $E$ is the Young's modulus, $\varepsilon$ is strain, whereas subscripts e and p denote the elastic and plastic components of strain, respectively, and $n$ is strainhardening exponent. Stress varies linearly with strain at elastic regime, whereas power law is obeyed at plastic regime. $\varepsilon_{\mathrm{p}}=0$ is possible only before the onset of plasticity. Therefore, power law is not valid in that region. Here, $\mathrm{K}$ can be taken as $\frac{\sigma_{\mathrm{y}}^{(1-n)}}{E^{n}}$ so that $\sigma_{y}$ and $n$ can only be chosen as input variables. The combination of $\sigma_{y}$ and $n$ that gives the best match between simulated and experimental load-displacement data, especially the unloading curve, is identified as the yield stress and strain-hardening exponent respective
Analysis on nanoindentation data to obtain elastic modulus for individual orientation

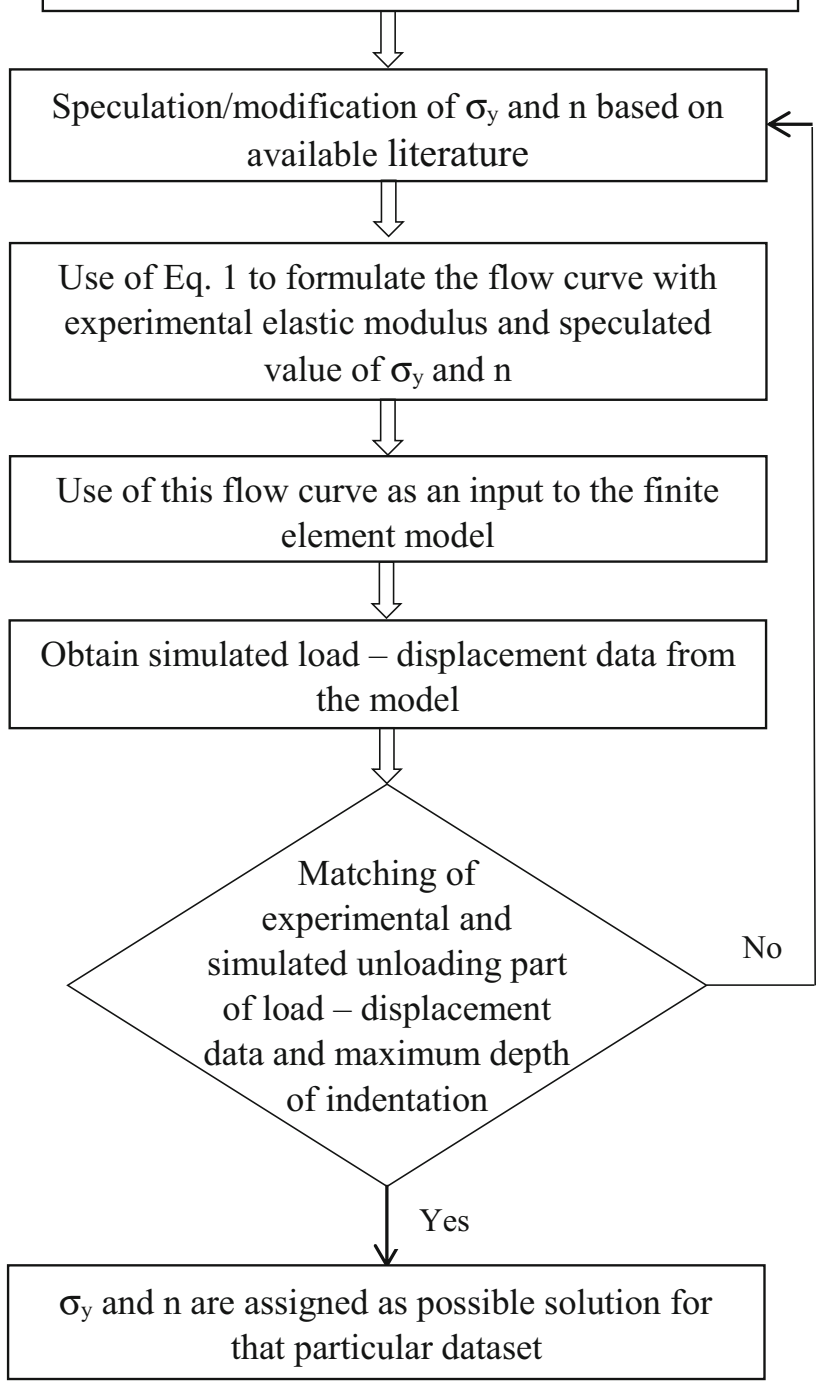

Figure 2 Flowchart describing input, procedure of finite element simulation and comparison between experiment and simulation.

to that particular orientation. Flowchart shown in Fig. 2 describes the procedure to generate input to the model using Eq. (1) and finite element simulation strategy to get a solution for $\sigma_{\mathrm{y}}$ and $n$. Solute strengthening effect in Zircaloy-2 was accounted in the model by elevating the guess values of $\sigma_{\mathrm{y}}$ or $n$ in comparison with crystal-bar $\mathrm{Zr}$ with similar orientation. 


\section{Results}

Figure $3 a, b$ shows typical EBSD images of nanoindented crystal-bar Zr and Zircaloy-2, respectively. Use of backscattered SEM signal plus IPF (inverse pole figure) orientation information was successful in bringing out the exact microstructural location of the nanoindents. This was essential to obtain orientationdependent load-displacement results. For example, crystal-bar $\mathrm{Zr}$ (Fig. 3a) was free from the second phase, while the clear presence of intermetallic precipitates and micro-twins was noted in the Zircaloy-2 (Fig. 3b). As stated earlier, only those nanoindentation measurements were selected which are from regions without visible 2nd phase, grain boundaries, and micro-twins in Zircaloy-2.

The binned data for hardness and elastic modulus, for both grades, are shown in Fig. 4 (36 data points for crystal-bar $\mathrm{Zr}$ and 80 data points for Zircaloy-2: each data point correspond to an orientation). In crystal-bar, hardness values range from $0.5 \mathrm{GPa}$ to 3 GPa. For a similar, albeit more extensive set of orientations, Zircaloy-2 hardness spread was 1.5 to 3 GPa. In other words, Zircaloy-2 did not exhibit the lower hardness values observed in crystal-bar (see
Fig. 4a). The observation on estimated elastic modulus was similar, see Fig. $4 b$, though the highest values estimated in Zircaloy-2 were marginally higher.

To formulate the local stress-strain behavior, nanoindentation simulations were performed using finite element method (as explained in "Finite element modeling" section). Figure 5a pictorially demonstrates the extent of matching of load-displacement behavior between experiments and simulations. As Oliver-Pharr analysis [33] is based on the unloading curve, emphasis was given to accurately predict the maximum indentation depth and unloading curve from FE simulations. Though FE simulations predicted yield stress and strain-hardening exponent, the ambiguity of multiple combinations of mechanical properties [19, 20, 24, 27, 32] was not avoided. Figure $5 b$ shows an example where the simulated unloading curve and maximum indentation depth matched with the experimental results equally well for two different sets of values of yield stress and strain-hardening exponent. In the discussion section, an attempt has been made to overcome this 'non-uniqueness' and predict a set of unique values.
Figure 3 Electron

backscattered diffraction (EBSD) images with combined information from backscattered detector and orientations [in inverse pole figure (IPF) notation] of nanoindented a crystal-bar zirconium and $\mathbf{b}$ Zircaloy-2. In b, micro-twins and secondphase precipitates are visible (shown by arrows). Only those indentations which were well inside grains (marked as square) were taken for analysis, and indentations close to grain boundary or twins (marked as circle) were excluded in the calculation.

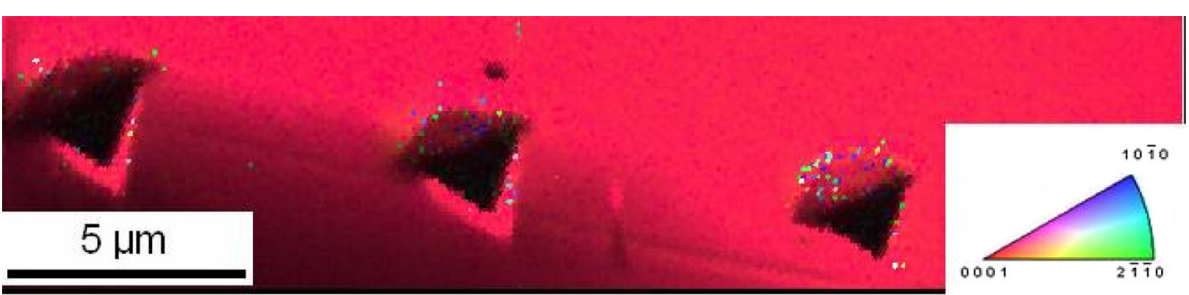

(a)

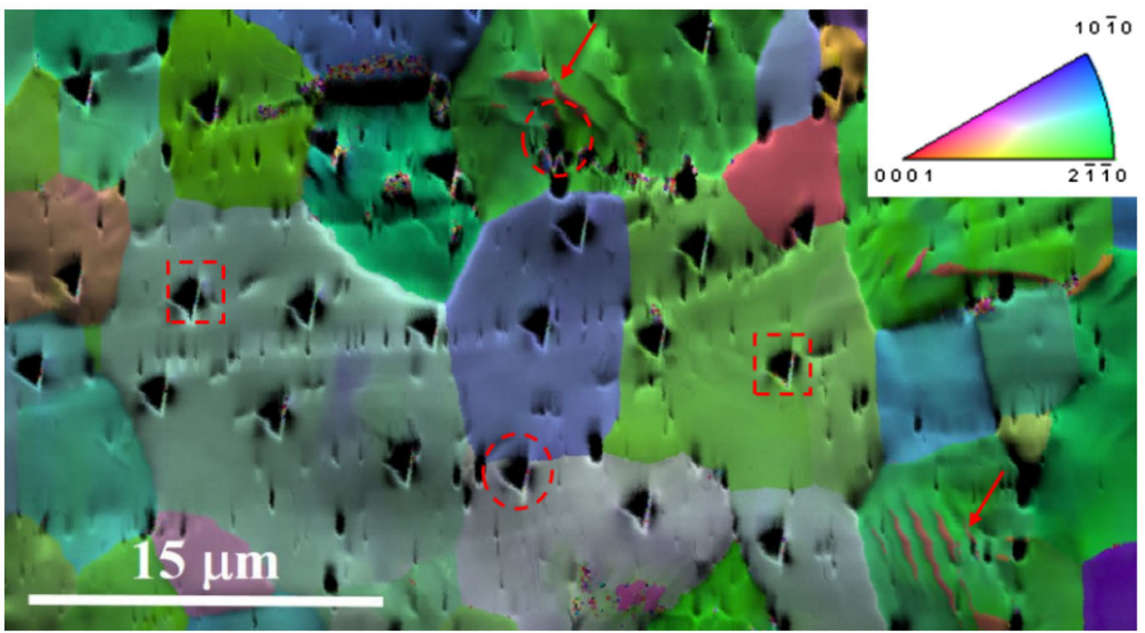

(b) 
Figure 4 Distribution of $\mathbf{a}$ hardness and $\mathbf{b}$ elastic modulus for crystal-bar zirconium and Zircaloy-2.
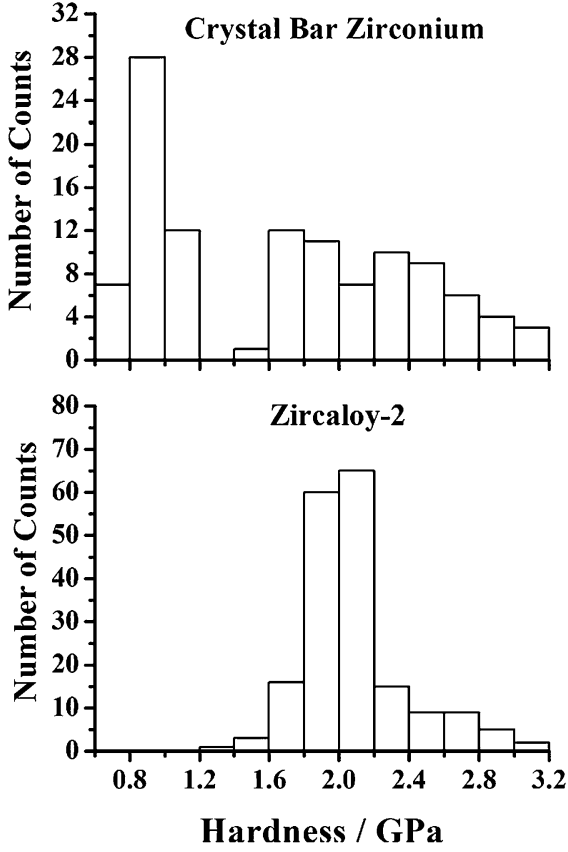

(a)
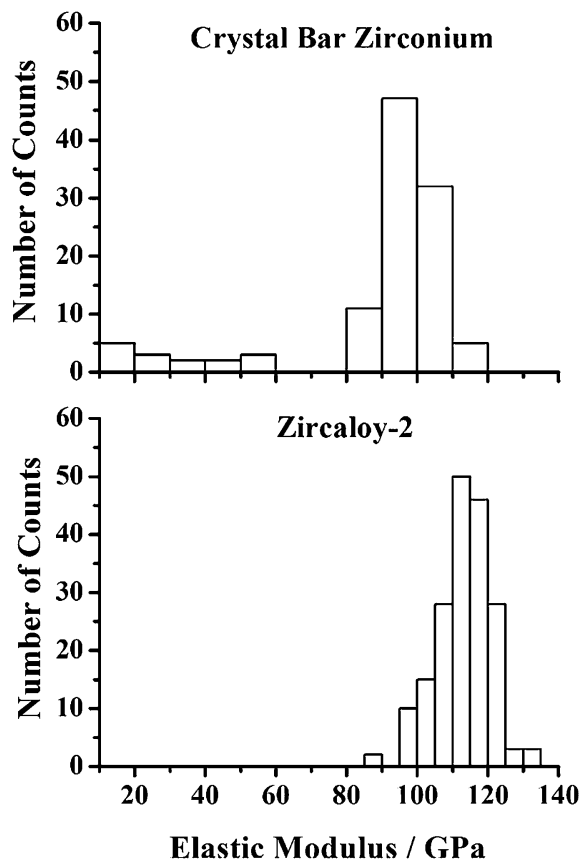

(b)
As shown in Fig. 6a, the near-surface plastic zones, after respective nanoindents, were effectively revealed through EBSD (electron backscattered diffraction). Relative misorientations from the quaternion average orientation are represented in color scale as the near-surface plastic zone. On the other hand, simulated plastic zone size was also calculated from effective plastic strain map (Fig. 6b). Simulations were performed assuming von Mises yield criterion. The effective plastic strain was calculated as, $\quad \varepsilon_{\text {effective }}=\sqrt{\frac{2}{3}\left(\varepsilon_{11}^{2}+\varepsilon_{22}^{2}+\varepsilon_{33}^{2}\right)} \quad$ where $\varepsilon_{11}, \varepsilon_{22}, \varepsilon_{33}$ are the principal strains calculated from FE simulations. A direct comparison between the zones would be questionable, as different criteria (effective strain versus local misorientation) were used. Hence, it was decided to consider a 'relative' effect. For both the grades (crystal-bar Zr versus Zircaloy-2), similar hardness values were chosen and zones were measured-see Table 2. Ratios of the hard-soft experimental and simulated zones were similar: 0.58 and 0.52 in Zircaloy-2, and 0.64 versus 0.72 in crystal-bar. This also highlights, albeit indirectly, the effectiveness of the nanoindentation simulations and negligible influence from grains below (the indenting grain) in experiments.

\section{Discussion}

Nano and pico indentations have the potential of estimating 'local' mechanical properties. This may bring insights into new aspects of microstructural developments and structure-property correlations. For this, the FE simulations [19, 22, 39] are essential. But as shown in this study, and also in the literature [19, 25, 27, 32], multiple solutions or ambiguities in the yield strength $\left(\sigma_{\mathrm{y}}\right)$ and strain-hardening exponent (n) values can provide a serious hindrance. This study proposes a possible solution. Figure 7 plots the experimental hardness $(H)$ versus FE simulated $\sigma_{\mathrm{y}}$. The extreme $\sigma_{\mathrm{y}}$ values, which show a good match in experimental and simulated nanoindentation curve, are shown as solid lines. The area between these maximum and minimum ranges, see Fig. 7, consists of all the possible solutions from FE. It was decided, as a convention, to take the mid-line, thus returning a constitutive relationship of $H=3.16 \sigma_{\mathrm{y}}$. It is to be noted that similar linear relationship $\left(H=3.16 \sigma_{\mathrm{y}}\right)$ was also reported in [38] for nominal hardness and yield stress corresponding to a representative strain. The maximum and minimum possibilities, Fig. 7, yield the coefficient of 3.40 and 2.92, respectively. Using $H=3.16 \sigma_{\mathrm{y}}$ does not avoid the non-uniqueness problem completely, but gives a means to obtain a solution closer to a unique value. These limits in 


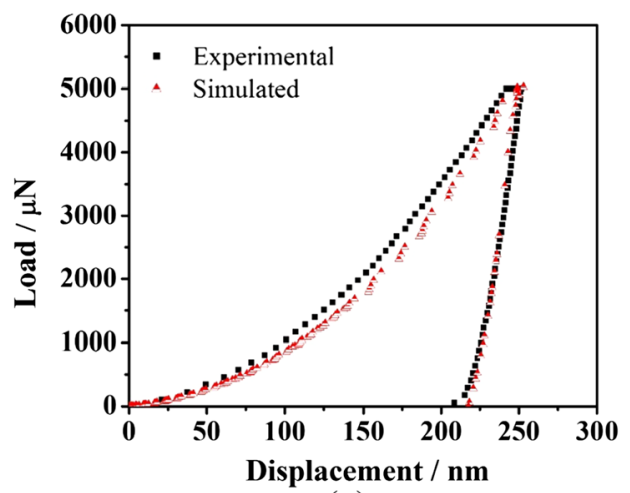

(a)

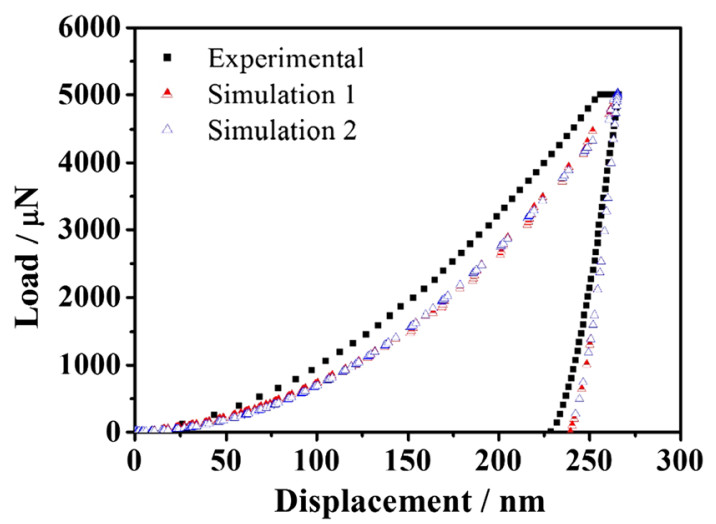

(b)

Figure 5 a Comparison between experimental and simulated load-displacement curves and $\mathbf{b}$ simulations showing multiple solutions for yield strength $\left(\sigma_{\mathrm{y}}\right)$ and strain-hardening exponent $(n)$. In $b$, simulations 1 and 2 , respectively, stipulate $\sigma_{\mathrm{y}}=600 \mathrm{MPa}$ and $656 \mathrm{MPa}$ and $n=0.17$ and 0.13 .

solution and the averaging 'scheme' to minimize non-uniqueness problem with FE indentation models were not reported before in the published literature. It is to be noted that the simulated stress-strain behaviors show much higher than the expected [40] strength values. This is not surprising, for example nanoindentation studies on $\mathrm{ZnO}$ and iron single crystals also reported significantly higher stress values than those obtained from conventional mechanical tests [41]. They proposed to multiply the bulk stress and strain values with respective factors of 3 and 10 to match it with nanoindentation derived values.

This opens up the possibilities of the use of nanoindentation data to expand on the solid solution strengthening and its possible orientation sensitivity. It is to be noted that Zircaloy-2 contains alloying elements, whereas crystal-bar zirconium is almost pure. Grain size strengthening can be neglected as the indentations stay well within the grain center in the analysis, so the comparison between hardness (or yield strength) of similar orientations provides indications only about solid solution strengthening. The change in hardness, for similar orientations, revealed clear 'anisotropy.' For example, hardening in basal/ near-basal was almost negligible $(\sim 4 \%)$, whereas nearly $100 \%$ increment in hardness was observed for non-basal orientations. The combination provided approximately $25 \%$ average hardening. A more complete picture can be seen in Fig. 8, which plots the hardness of individual grains as a function of deviation from the basal plane $(\delta)$. It is well known that the near-basal hardness is highest in zirconium $[12,42]$. Comparing crystal-bar $\mathrm{Zr}$ (pure $\mathrm{Zr}$ ) with commercial-purity Zircaloy-2 clearly revealed that the solid solution strengthening was effective only to the weaker non-basal orientation, and did not alter the hardness or stress-strain behavior of the nearbasal grains. They had the highest, but similar, hardness (and stress-strain responses) in both grades of Zr. This study thus brought out clearly that the solid solution strengthening is restricted to the crystallographically weaker grains or orientations. Of course, in commercial Zircaloy-2 microscopic composition heterogeneities are expected. However, analytical microscopy (energy or wavelength-dispersive X-ray spectroscopy) with sub-micron resolution did not reveal significant variation in composition inside the grains. More importantly, the experimental load-displacement plots were almost identical when grains of the same crystallographic orientations were considered (Fig. 9).

A modern crystal plasticity model (for example, a full-field crystal plasticity finite element model) uses the overall stress-strain responses [15, 43-46]. The orientation dependence is introduced with dislocation-based latent hardening [46]. The latter is, however, ad-hoc. The present study introduces the possibility of calibrating such ad-hoc latent hardening values with robust experimental data (Fig. 10). The present FE model was used to expand on the anisotropic hardening, see Fig. 10. Three distinct, but similar orientations, for both grades, were selected for comparison. It is expected that solid solution hardening would push the yield strength and strainhardening exponent to a higher value. Increasing these values, in comparison with crystal-bar $\mathrm{Zr}$ with similar orientation, accounted for the solute strengthening effect in the FE model. Introducing the 
Figure 6 a Data from Fig. 3a with detector signal plus relative misorientation.

Average orientation (quaternion average: shown as a unit cell) was calculated. Relative misorientation, from the average orientation, was then plotted in the attached color code. Thus, a provides an estimate of the near-surface plastic zone; $\mathbf{b}$ effective plastic strain map obtained from FE simulations.
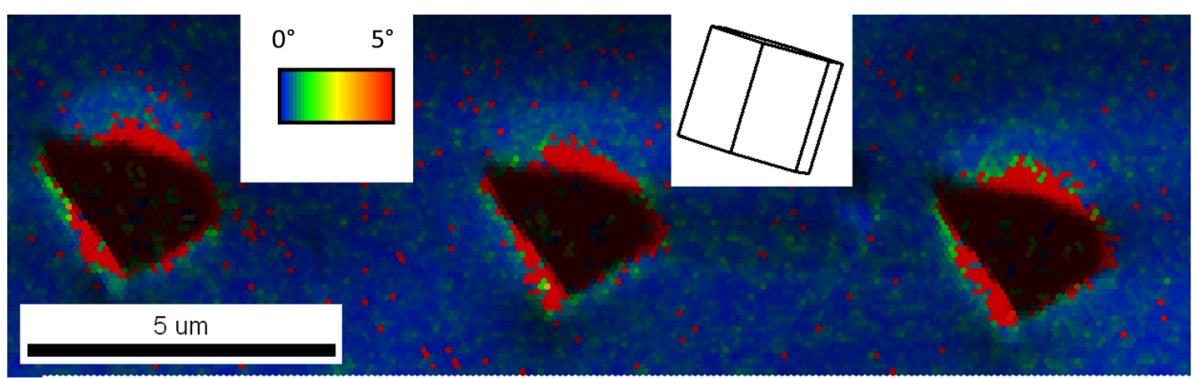

(a)

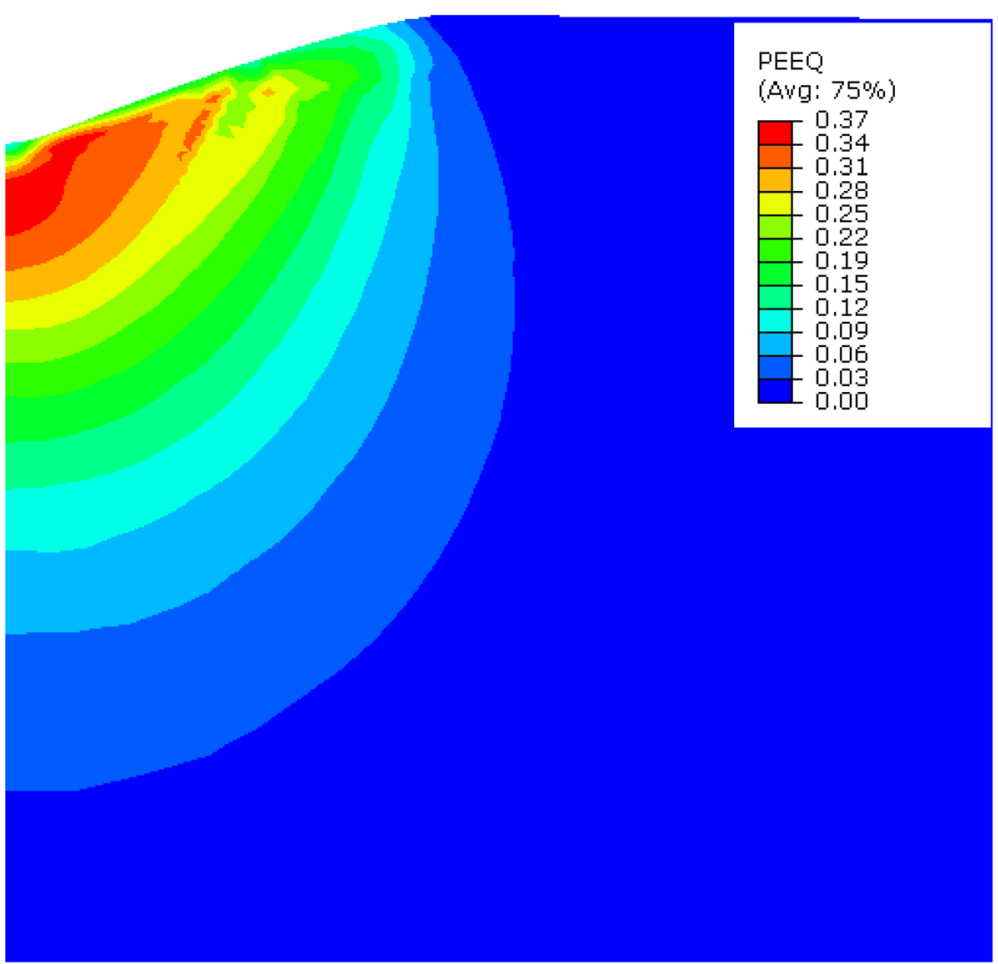

(b)

Table 2 Comparison of plastic zone size between experiment and simulation

\begin{tabular}{llllll}
\hline Sample & $\begin{array}{l}\text { Hardness } \\
(\mathrm{GPa})\end{array}$ & $\begin{array}{l}\text { Experimental plastic } \\
\text { zone size }(\mu \mathrm{m})\end{array}$ & $\begin{array}{l}\text { Simulated plastic } \\
\text { zone size }(\mu \mathrm{m})\end{array}$ & $\begin{array}{l}\text { Ratio of experimental plastic } \\
\text { zone size }(\mathrm{min} / \mathrm{max})\end{array}$ & $\begin{array}{l}\text { Ratio of simulated plastic } \\
\text { zone size }(\min / \mathrm{max})\end{array}$ \\
\hline Zircaloy-2 & 2.95 & 0.72 & 0.57 & 0.58 & 0.52 \\
& 1.59 & 1.25 & 1.1 & 0.64 & 0.72 \\
Crystal-bar & 2.99 & 0.98 & 0.72 & & \\
zirconium & 1.59 & 1.56 & 1.01 & \\
\hline
\end{tabular}

higher values was attempted through multiple iterations. For example, as shown in Fig. 10, yield stress values for orientation $\mathrm{B}$ or $\mathrm{C}$ in inverse pole figure for crystal-bar $\mathrm{Zr}$ were low ( $250 \mathrm{MPa})$. On the other hand, it shifted to $\sim 600 \mathrm{MPa}$ in Zircaloy-2 for similar orientations. Similarly, changes in strain-hardening exponent, between the two alloys for these orientations, were also imposed (see Fig. 10). Critical resolved shear stress (CRSS), measured for basal slip versus prism slip, for high-purity zirconium single crystals (with varied oxygen content) also showed marked differences $[12,41]$. This is typically explained in terms of the critical resolved shear stresses of the respective slip systems. Anisotropic

\section{Springer}




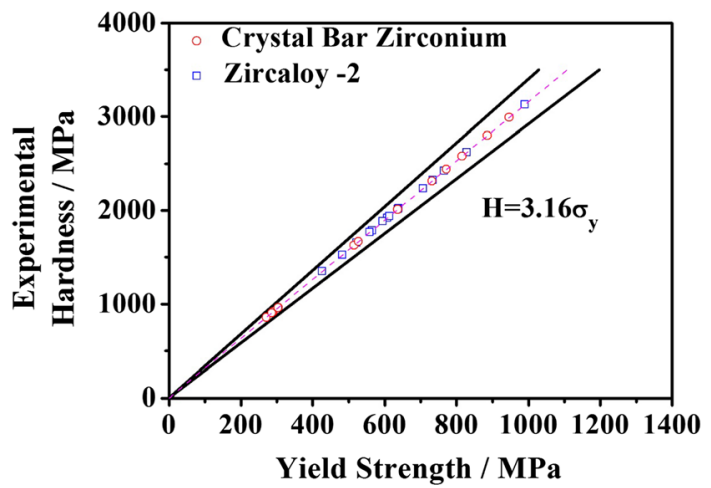

Figure 7 Relation between experimental hardness and simulated yield stress. The maximum and minimum yield strengths, from the FE simulations, are used to show the extremities of constitutive relations. The middle line, or a constitutive relation of $H=3.16 \sigma_{\mathrm{y}}$ (where $H=$ experimental hardness and $\sigma_{\mathrm{y}}=$ extrapolated yield strength), was then used.

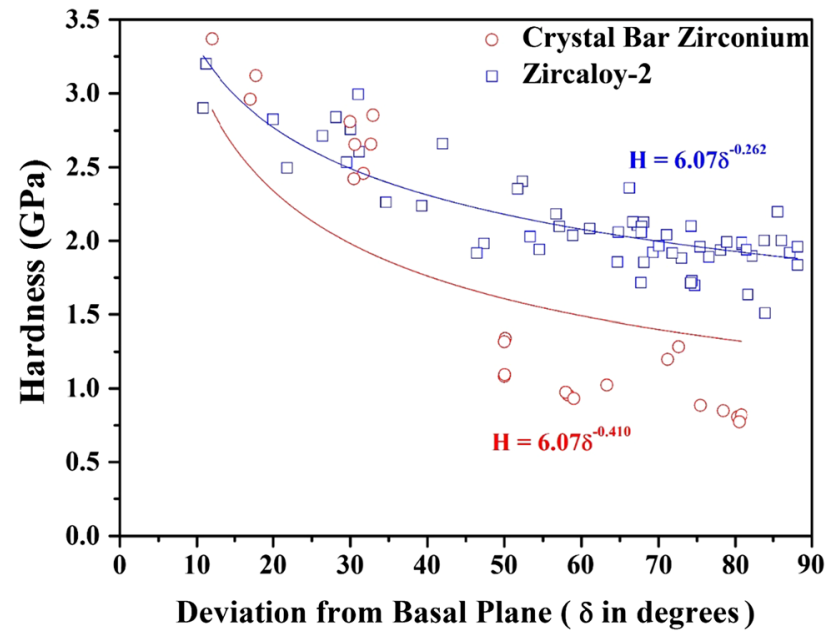

Figure 8 Variation of hardness as a function of deviation from the basal plane. These are shown for both crystal-bar and Zircaloy-

load-displacement and stress-strain responses were discussed for hexagonal $\mathrm{Zr}$-there are a 'limited' number of references $[47,48]$. However, there are no references on anisotropic load-displacement and stress-strain responses between high-purity (crystalbar $\mathrm{Zr}$ ) and commercial-purity single-phase Zircaloy2. In this study, the comparison of similar hardness values (and stress-strain responses) between the two grades (high-purity crystal-bar $\mathrm{Zr}$ versus commercial-purity Zircaloy-2) clearly revealed that the alloying 'pushed' the CRSS for non-basal orientations but had negligible impact on basal orientations. Such

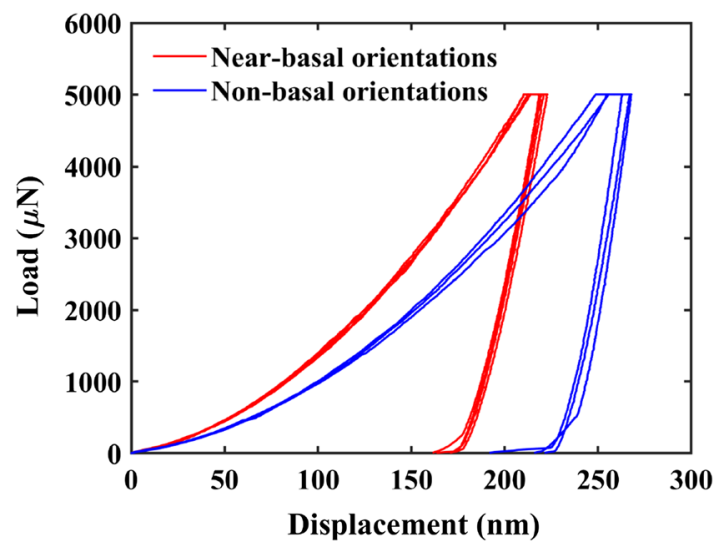

Figure 9 Experimental load-displacement plots of two different sets of orientations in Zircaloy-2. For each set, different grains with similar orientations were indented. Negligible difference is observed within a set, while significant variation exists between the two sets.

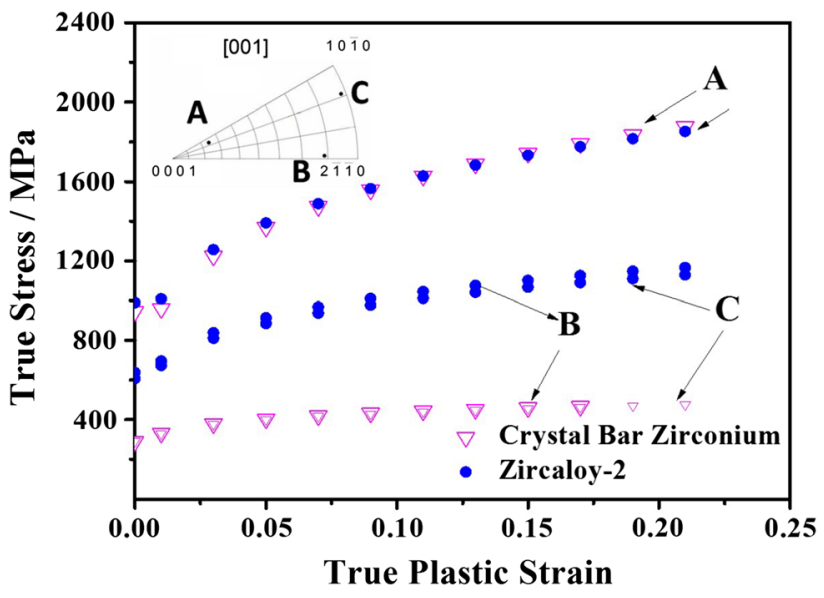

Figure 10 Simulated stress-strain (plastic) plots show the anisotropic hardening for three distinct, but similar orientations (A, B and C: as marked in the IPF) for crystal-bar zirconium and Zircaloy-2.

information is intrinsically novel and never been published before.

\section{Conclusions}

This study involved orientation-dependent nanoindentation measurements in high-purity zirconium crystal-bar and in commercial Zircaloy-2. Zircaloy-2 had, on average, 25-28\% higher hardness and elastic stiffness than $6 \mathrm{~N}$ (99.9999 wt\% Zr) purity crystal-bar. The shift in mechanical properties was anisotropic- 
elimination of lower hardness/stiffness with insignificant changes in the highest value.

The nanoindentation plots were converted to stress-strain behaviors through appropriate finite element modeling of the unloading part. The proposed scheme of 'averaging' and a constitutive relationship can predict toward a unique solution. This, on the other hand, helped in the effective study of the orientation-dependent solid solution strengthening. The increment in hardness due to solid solution strengthening was negligible in the hard basal/nearbasal crystallographic orientations, and significant in the softer non-basal orientations.

\section{Acknowledgements}

The authors would like to express their appreciations for the support from BRNS (Board of Research on Nuclear Sciences), Nanoindentation facility at Metallurgical Engineering and Materials Science (MEMS), IIT Bombay, and National Facility of Texture and OIM (a DST-IRPHA project), IIT Bombay.

Open Access This article is licensed under a Creative Commons Attribution 4.0 International License, which permits use, sharing, adaptation, distribution and reproduction in any medium or format, as long as you give appropriate credit to the original author(s) and the source, provide a link to the Creative Commons licence, and indicate if changes were made. The images or other third party material in this article are included in the article's Creative Commons licence, unless indicated otherwise in a credit line to the material. If material is not included in the article's Creative Commons licence and your intended use is not permitted by statutory regulation or exceeds the permitted use, you will need to obtain permission directly from the copyright holder. To view a copy of this licence, visit http://creativecommons.org/licen ses/by/4.0/.

\section{References}

[1] Lamarsh JR, Baratta AJ (2013) Introduction to Nuclear Engineering: Pearson New International Edition, Pearson Higher Ed.

[2] McKay A (1984) The making of the atomic age. Oxford University Press, Oxford
[3] Verlinden B, Driver J, Samajdar I, Doherty RD (2007) Thermo-mechanical processing of metallic materials. Elsevier, Amsterdam

[4] Northwood DO (1985) The development and applications of zirconium alloys. Mater Des 6:58-70

[5] Northwood DO, Kosasih U (1983) Hydrides and delayed hydrogen cracking in zirconium and its alloys. Int Metals Rev 28:92-121

[6] Opeka MM, Talmy IG, Wuchina EJ et al (1999) Mechanical, thermal, and oxidation properties of refractory hafnium and zirconium compounds. J Eur Ceram Soc 19:2405-2414

[7] Massalski TB, Okamoto H, Subramanian PR, Kacprzak L (1990) Binary alloy phase diagrams, 2nd edn. ASM International, Ohio

[8] Dieter GE, Bacon DJ (1986) Mechanical metallurgy. McGraw-Hill, New York

[9] Rittenhouse PL, Picklesimer ML (1966) Research on the mechanical anisotropy of zircaloy-2. Electrochem Technol 4:322-329

[10] Rittenhouse PL (1967) Determination of the anisotropy of yielding and flow in Zircaloy-2 from a single test. J Nucl Mater 23:183-191

[11] Picklesimer ML (2010) Anisotropy in Zircaloy. In: Adamson $\mathrm{R}$ (ed) Zirconium production and technology: the kroll medal papers 1975-2010. ASTM International, West Conshohocken, PA, pp 91-102. https://doi.org/10.1520/MN L12106R. Original paper was published by ASTM International in STP 939, Zirconium in the Nuclear Industry: Seventh International Symposium, 1987, pp 23-34

[12] Akhtar A, Teghtsoonian A (1971) Plastic deformation of zirconium single crystals. Acta Metall 19:655-663

[13] Kubo T, Wakashima Y, Amano K, Nagai M (1985) Effects of crystallographic orientation on plastic deformation and SCC initiation of zirconium alloys. J Nucl Mater 132:1-9

[14] Tenckhoff E (1988) Deformation mechanisms, texture, and anisotropy in zirconium and zircaloy. ASTM International, West Conshohocken

[15] Lebensohn RA, Tomé CN (1993) A self-consistent anisotropic approach for the simulation of plastic deformation and texture development of polycrystals: application to zirconium alloys. Acta Metall Mater 41:2611-2624

[16] Murty KL, Charit I (2006) Texture development and anisotropic deformation of zircaloys. Prog Nucl Energy 48:325-359

[17] Sahoo SK, Hiwarkar VD, Samajdar I et al (2007) Heterogeneous deformation in single-phase Zircaloy 2. Scr Mater 56:963-966

[18] Dao M, van Chollacoop N, Van Vliet KJ et al (2001) Computational modeling of the forward and reverse 
problems in instrumented sharp indentation. Acta Mater 49:3899-3918

[19] Cheng Y-T, Cheng C-M (2004) Scaling, dimensional analysis, and indentation measurements. Mater Sci Eng R Rep 44:91-149

[20] Tho KK, Swaddiwudhipong S, Liu ZS, Zeng K (2005) Simulation of instrumented indentation and material characterization. Mater Sci Eng, A 390:202-209

[21] Antunes JM, Fernandes JV, Menezes LF, Chaparro BM (2007) A new approach for reverse analyses in depth-sensing indentation using numerical simulation. Acta Mater $55: 69-81$

[22] Shim S, Jang J, Pharr GM (2008) Extraction of flow properties of single-crystal silicon carbide by nanoindentation and finite-element simulation. Acta Mater 56:3824-3832

[23] Pathak S, Stojakovic D, Kalidindi SR (2009) Measurement of the local mechanical properties in polycrystalline samples using spherical nanoindentation and orientation imaging microscopy. Acta Mater 57:3020-3028

[24] Cheng Y-T, Cheng C-M (1999) Can stress-strain relationships be obtained from indentation curves using conical and pyramidal indenters? J Mater Res 14:3493-3496

[25] Chen X, Ogasawara N, Zhao M, Chiba N (2007) On the uniqueness of measuring elastoplastic properties from indentation: the indistinguishable mystical materials. J Mech Phys Solids 55:1618-1660

[26] Liu L, Ogasawara N, Chiba N, Chen X (2009) Can indentation technique measure unique elastoplastic properties? J Mater Res 24:784-800

[27] Lan H, Venkatesh TA (2007) On the uniqueness and sensitivity issues in determining the elastic and plastic properties of power-law hardening materials through sharp and spherical indentation. Philos Mag 87:4671-4729

[28] Bauri R, Pancholi V, Samajdar I, Surappa MK (2005) Relating microtexture and dynamic micro hardness in an extruded AA8090 alloy and AA8090-8 vol\% SiCp composite. Sci Technol Adv Mater 6:933-938

[29] Yoshinaga H, Horiuchi R (1963) On the flow stress of $\sigma$ solid solution mg-li alloy single crystals. Trans Jpn Inst Metals 4:134-141

[30] Ando S, Tonda H (2000) Non-basal slip in magnesium-lithium alloy single crystals. Mater Trans, JIM 41:1188-1191

[31] Akhtar A, Teghtsoonian E (1969) Solid solution strengthening of magnesium single crystals - I alloying behaviour in basal slip. Acta Metall 17:1339-1349

[32] Lodh A, Samajdar I, Tewari R et al (2012) Effects of grain orientations on nanoindentation behavior in hexagonal zirconium. Mater Sci Forum 702:311-314

[33] Oliver WC, Pharr GM (1992) An improved technique for determining hardness and elastic modulus using load and displacement sensing indentation experiments. J Mater Res $7: 1564-1583$

[34] Hertz H, Jones DE, Schott GA (1896) Miscellaneous papers. Macmillan and Company, New York

[35] Fischer-Cripps AC (2011) Nanoindentation testing. In: Nanoindentation. Springer, New York, pp 21-37

[36] Meng X, Northwood DO (1989) Second phase particles in Zircaloy-2. J Nucl Mater 168:125-136

[37] https://www.hysitron.com/media/1683/t-003-v30-probe-cali bration.pdf

[38] Douglass DL (1963) The physical metallurgy of zirconium. At Energy Rev 1:71-237

[39] Beghini M, Bertini L, Fontanari V (2006) Evaluation of the stress-strain curve of metallic materials by spherical indentation. Int J Solids Struct 43:2441-2459

[40] Wadekar SL, Raman VV, Banerjee S, Asundi MK (1988) Structure-property correlation of Zr-base alloys. J Nucl Mater 151:162-171

[41] Basu S, Moseson A, Barsoum MW (2006) On the determination of spherical nanoindentation stress-strain curves. J Mater Res 21:2628-2637

[42] Akhtar A (1973) Basal slip in zirconium. Acta Metall 21:1-11

[43] Marin EB (2006) On the formulation of a crystal plasticity model. SANDIA Technical Report, US, pp 1-62. https://doi. org/10.2172/890604

[44] Anand L, Kothari M (1996) A computational procedure for rate-independent crystal plasticity. J Mech Phys Solids 44:525-558

[45] Roters F, Eisenlohr P, Hantcherli L et al (2010) Overview of constitutive laws, kinematics, homogenization and multiscale methods in crystal plasticity finite-element modeling: theory, experiments, applications. Acta Mater 58:1152-1211

[46] Lodh A, Tewary U, Singh RP et al (2018) Orientation-dependent developments in misorientation and residual stress in rolled aluminum: the defining role of dislocation interactions. Metall Mater Trans A Phys Metall Mater Sci 49:5946-5952

[47] Pathak S, Kalidindi SR, Mara NA (2016) Investigations of orientation and length scale effects on micromechanical responses in polycrystalline zirconium using spherical nanoindentation. Scr Mater 113:241-245

[48] Gong J, Benjamin Britton T, Cuddihy MA et al (2015) $\langle\mathrm{a}\rangle$ Prismatic, $\langle\mathrm{a}\rangle$ basal, and $\langle\mathrm{c}+\mathrm{a}\rangle$ slip strengths of commercially pure $\mathrm{Zr}$ by micro-cantilever tests. Acta Mater 96:249-257

Publisher's Note Springer Nature remains neutral with regard to jurisdictional claims in published maps and institutional affiliations. 